\title{
Frequency and histologic characterization of coelomatic neoplasms in koi Cyprinus carpio koi
}

\author{
F. Ott Knüsel ${ }^{1, *}$, R. Knüsel ${ }^{1}$, M. G. Doherr ${ }^{2}$, H. Schmidt-Posthaus ${ }^{3}$ \\ ${ }^{1}$ fishdoc GmbH, Schaubhus, 6026 Rain, Switzerland \\ ${ }^{2}$ Institute for Veterinary Epidemiology and Biostatistics, Freie Universität, Königsweg 67, 14163 Berlin, Germany \\ ${ }^{3}$ Centre for Fish and Wildlife Health, Department of Infectious Diseases and Pathobiology, Vetsuisse Faculty, \\ University of Bern, Länggassstrasse 122, 3001 Bern, Switzerland
}

\begin{abstract}
Koi carp presenting with coelomatic neoplastic lesions are of growing importance in Switzerland and elsewhere in Europe, as clinical diagnosis is usually difficult and prognosis is usually poor because of late recognition. To gain more information about this condition, between 2008 and 2012, 117 koi diagnosed with coelomatic tumours were included in this study. The nature and growth characteristics of these pathologic tissues were documented. Out of 117 koi, $48.9 \%(n=57)$ were female; the ovary was the most often affected organ $(35 \%, n=41)$, and in $62.4 \%(n=73)$ of cases, the cells of origin were identified as stromal cells of the sex-cord and the tumours were identified as sex-cord stromal tumours. The characteristics of growth and histology showed that the majority of tumours were malignant.
\end{abstract}

KEY WORDS: Koi carp $\cdot$ Neoplasm $\cdot$ Histopathology $\cdot$ Ovary $\cdot$ Testis $\cdot$ Sex-cord stromal tumour

Resale or republication not permitted without written consent of the publisher

\section{INTRODUCTION}

Koi Cyprinus carpio koi, the ornamental variety of common carp, is a freshwater fish of the family Cyprinidae. It has a long life span in domestication (up to $40 \mathrm{yr}$, see fishbase.org) and is gaining popularity in many countries worldwide. Koi can have high economical value and become very tame and therefore may have a high emotional value for their owners (Carey \& Judge 2000).

To date, only few studies have reported on the occurrence of tumours in koi carp (Ishikawa \& Takayama 1977, Knüsel et al. 2007, Sirri et al. 2010, 2012, Ott Knüsel et al. 2015). The few existing records report on neoplastic proliferations in the gills, liver, gonads and kidneys. The aetiology of the tumour occurrence in gills or kidney seems to be unknown. According to our own experience, the occurrence of tumours in internal organs seems to be severely underestimated. Neoplastic lesions of internal organs are a regular finding, with case numbers steadily increasing over recent years (Ott Knüsel et al. 2015, pers. obs.). Clinically, these fish present an abnormal swelling of the abdomen, often in late summer after the spawning season. The cause of the swelling has to be ruled out by surgery or pathologically, with egg retention as the main differential diagnosis. In a recent study, the frequency of coelomatic tumours in a selected koi population in Switzerland was investigated (Ott Knüsel et al. 2015). Out of 9300 fish included in the study, $1.2 \%$ developed coelomatic tumours between 2008 and 2012. This equates to 22.4 tumour cases per year, or $0.24 \%$ of the whole diagnostic material of our veterinary clinic (fishdoc $\mathrm{GmbH}_{\text {; }}$ www.fishdoc.ch). As the incidental tumour occurrence in other ornamental fish species is rare, an incidence of $0.24 \%$ per year was interpreted as high (Ott Knüsel et al. 2015). Most of the affected koi (62\%) were less than 6 yr old. 
To gain more information about the nature of neoplastic lesions in internal organs and the pathological features of these neoplasms, koi presenting with various abdominal neoplasms were examined between 2008 and 2012. Specifically, possible sex-specific differences, the organs affected, the tissue/cells of origin and the characteristics of neoplastic growth were investigated.

\section{MATERIALS AND METHODS}

\section{Origin of samples}

Between 2008 and 2012, all koi carp with an enlarged abdomen, which were euthanized or died in our veterinary clinic, were examined pathologically. A standard necropsy was performed. Those fish showing a coelomatic mass suspected to be a tumour were included in this study, for a total of 117 animals. As there was no recurrence of tumour masses in the same animal, 1 tumour case always corresponds to 1 animal. If possible, the sex of the affected animal was recorded. Macroscopic changes of internal organs, including extent and appearance of the coelomatic mass (colour, surface, cut section and texture) were recorded in 62 cases. In all 117 cases, tissue samples of different representative areas were fixed and stored in $10 \%$ buffered formalin and sent for analysis to the Centre for Fish and Wildlife Health (University of Bern). These samples were identified histologically as coelomatic neoplastic lesions. This criterion was used for the final decision to include the animals in this study.

\section{Histopathology and immunohistochemistry (IHC)}

Formalin-fixed samples were paraffin-embedded and routinely processed. Three or 4 serial sections were prepared: the first sections were stained with haematoxylin-eosin (H\&E), the remaining sections were used for IHC staining.

As a basis to classify the neoplasms, criteria defined in the World Health Organization classifications for tumours in domestic animals (Kennedy et al. 1998, Head et al. 2003, Meuten et al. 2007) were used.

Because of limited availability of antibodies working properly on our koi carp tissue, only an epithelial cell type marker and a marker recognising cell-cell adhesions were used for IHC. First, a broad-spectrum antibody recognising most of the 19 human cytokeratins (Cytokeratin [CK] AE1/AE3, Dako; dilution 1:50) was
Table 1. Reaction pattern of monoclonal antibodies used in reference tissue originating from healthy koi carp Cyprinus carpio koi. +: low positivity with used antibody, faint staining $_{i}++$ : moderate positivity, moderate staining $;+++$ : strong positivity, strong staining; - : no staining

\begin{tabular}{|lcc|}
\hline & Cytokeratin AE1/AE3 & E-cadherin \\
\hline Intestinal mucosa & ++ & ++ \\
Exocrine pancreas & ++ & + \\
Hepatocytes & - & + \\
Bile duct epithelial cells & +++ & ++ \\
Endothelia & + & - \\
Adipocytes & +++ & - \\
Granulosa cells & $+/-$ & + \\
Ovary epithelial cells & $+/-$ & + \\
Interstitial cells & - & - \\
\hline
\end{tabular}

used. Specificity is described for a number of fish species, including striped bass Morone saxatilis and medaka Oryzias latipes (Bunton 1993) or Atlantic salmon Salmo salar and rainbow trout Oncorhynchus mykiss (Dale et al. 2009). To test the reactivity in carp tissue, normal carp liver, intestine and gonads (ovary and testis) were tested and a score was formulated according to low, moderate or strong signals obtained (Table 1, Fig. 1). Second, a monoclonal antibody targeting the epithelial cell adhesion molecule, E-cadherin (anti-E-cad, BD Biosciences; dilution 1:100), was used ( $\mathrm{Ng}$ et al. 2005). E-cadherin acts as an invasion suppressor molecule, mainly expressed in non-invasive, well-differentiated tumour types. Alternatively, with increasing invasiveness, expression is suppressed (Vleminckx et al. 1991, Singhai et al. 2011). Again, reactivity on carp tissue was tested on normal carp liver, intestine and gonads (ovary and testis) and a score was formulated according to low, moderate or strong signal obtained (Table 1, Fig. 1). The intestine was selected as a positive control, as reactivity was previously investigated by Dale et al. (2009). Liver and gonadal tissues were selected to demonstrate the reactivity pattern of the markers used in this study on normal carp tissue. As positive controls, dog liver and a fish control of carp liver and intestine were used.

Histologically, organ/tissue/cell of tumour origin, characteristics of growth and cell and nuclear morphology were examined and tumours were classified. With a few exceptions, most of the slides per case showed identical parameters. In cases of nonconformity, the average parameter value was determined by evaluating up to 4 slides. The growth patterns were classified according to the following criteria: encapsulation, demarcation, infiltrative versus expansive growth, degree of cell atypia (cell and nuclear pleomorphism), extension of necrosis, and fre- 


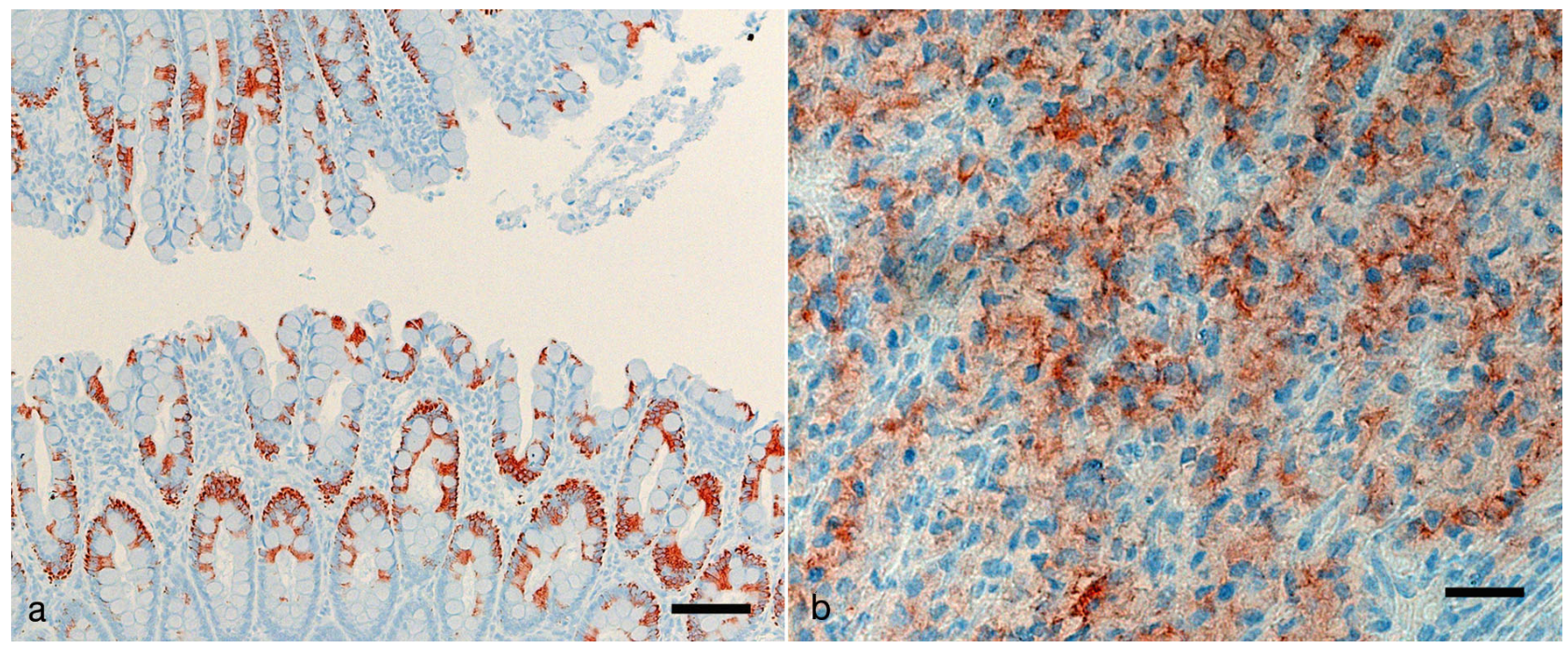

Fig. 1. Immunohistochemical staining. (a) Normal epithelial cells of the intestinal mucosa of koi Cyprinus carpio koi show cytoplasmic positive staining for Cytokeratin AE1/AE3. (b) Tumour cells of the liver show cytoplasmic and membranous positive staining for E-cadherin (anti-E-cad) staining, haematoxylin counterstaining. Scale bars $=25 \mu \mathrm{m}$

quency of mitotic figures per 400x field (high power field, $\mathrm{HPF}_{\text {; }}$ Table 2) assigning a score from 0 to 3 to each parameter. In cases where no original organ tissue was visible on the histological slides, the organ of origin was assigned to the predominant tumour tissue and indicated as such thereafter. If no organ could be defined, organ of origin was classified as unknown. A final tumour diagnosis was made based on the histological appearance.

\section{Statistics}

All animals included in this study showed neoplastic lesions. The neoplasms originated only from single organs, and each tumour was only counted once per animal (no recurrence of neoplasms). Data were stored in Microsoft Excel 2010 and analysed using the statistical software package NCSS 8 (www.ncss.com). All variables were described using standard statistics depending on measurement scale and checked for errors, extreme values and categories with sparse data. Due to the subjective ordinal nature of the scores used to measure the various histopathological characteristics, their association was assessed using nonparametric statistical routines. Median scores of one measure were compared between score levels (classes) of another measure using the Kruskal-Wallis ANOVA on ranks (Kruskal-Wallis test, KWT) with adjustment for ties, followed by Dunn's test (z-value) with adjustment for multiple comparisons. In addition, Fisher's exact test (FET) statistics were derived from frequencies (counts) within pairwise cross-tables, treating different score values as distinct classes. We used a significance level of $\alpha=0.05$.

\section{RESULTS}

\section{Overview}

Up to 4 slides per case were evaluated; total case number was 117, sampled between 2008 and 2012. The countries of origin of the sampled koi were Switzerland (112), Austria (2), Germany (2) and Liechtenstein (1). Most of the samples were taken from koi from clients of our veterinary clinic; 8

Table 2. Overview of growth parameters of coelomatic tumours in koi Cyprinus carpio koi. Range of score values was applied to each parameter independently (na: index value not applicable to parameter). HPF: high power field (400× magnification)

\begin{tabular}{|c|c|c|c|c|c|}
\hline \multirow{2}{*}{$\begin{array}{l}\text { Score } \\
\text { value }\end{array}$} & \multirow[b]{2}{*}{$\begin{array}{c}\text { Cell } \\
\text { atypia }\end{array}$} & \multirow{2}{*}{$\begin{array}{l}\text { Mitotic frequency } \\
\text { (figures } \mathrm{HPF}^{-1} \text { ) }\end{array}$} & \multirow{2}{*}{$\begin{array}{l}\text { growth paramet } \\
\text { Necrosis } \\
\text { of tissue }\end{array}$} & \multirow[b]{2}{*}{$\begin{array}{l}\text { Infiltrative } \\
\text { growth }\end{array}$} & \multirow[b]{2}{*}{$\begin{array}{l}\text { Encapsu- } \\
\text { lation }\end{array}$} \\
\hline & & & & & \\
\hline 0 & None & None & None & None & None \\
\hline 1 & Medium & Low $(1-2)$ & Partial, small areas & Scattered & Partial \\
\hline 2 & High & Medium (3-5) & Partial, large areas & Moderate & Complete \\
\hline 3 & na & High $(>5)$ & Most necrotic & Severe & na \\
\hline
\end{tabular}



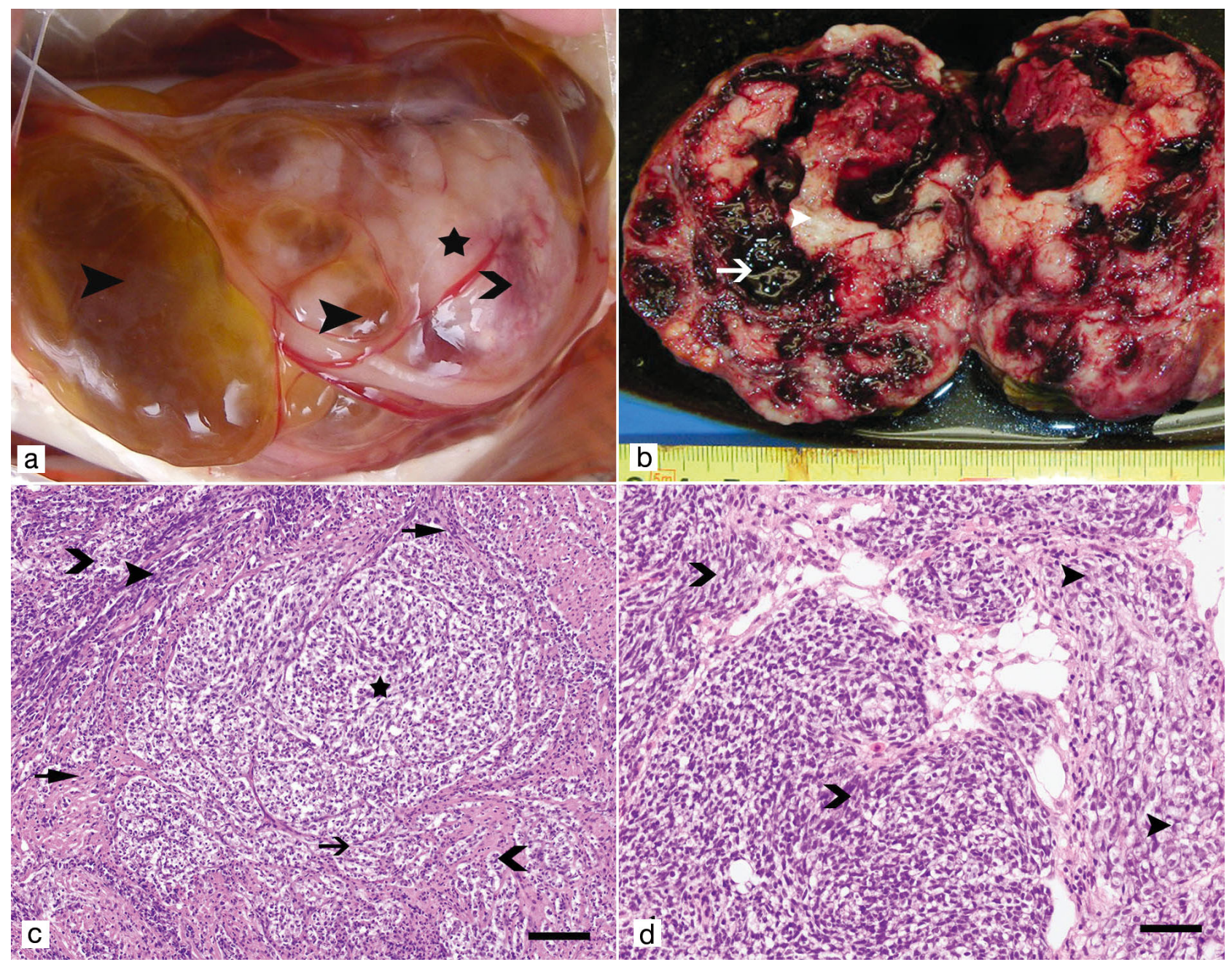

Fig. 2. Sex-cord stromal tumour in the ovary of koi Cyprinus carpio koi. (a,b) Macroscopic appearance, multinodular and cystic appearance: (a) cysts are filled with yellowish fluid (closed arrowhead), multiple solid whitish nodular parts (star) and multifocal haemorrhages (open arrowhead); (b) multiple cysts of variable size, filled with dark reddish fluid (arrow with open arrowhead), few whitish nodular parts (closed arrowhead). (c,d) Microscopic appearance: (c) tumour cells are arranged in groups (star) and bundles (closed arrowhead) with a moderate amount of fibrovascular stroma (arrows with closed arrowhead), tumour cells are polygonal (star) to elongated (closed arrowheads). Polygonal cells showed intracytoplasmic vacuoles. Multifocally there are small areas of necrosis (open arrowheads) and a mild infiltration with mainly lymphocytes (arrow with open arrowhead); (d) higher magnification showing different types of tumour cells, polygonal cells with vacuolated cytoplasm (closed arrowheads) and more elongated cells with small hyperchromatic nuclei (open arrowheads). H\&E staining. Scale bars $=(\mathrm{c}) 50 \mu \mathrm{m},(\mathrm{d}) 25 \mu \mathrm{m}$

tumour samples were sent from other specialized fish veterinarians.

\section{Clinical signs}

Ultimately in all cases, the owner or the veterinarian noticed an abnormal abdominal swelling in the affected koi (see also Ott Knüsel et al. 2015). The swelling was more or less uniform, firm to the touch and bilateral, and only few tumours showed a more unilateral appearance. Despite a severe distension of the abdomen, the koi usually showed normal behaviour. Often, the affected animals showed an increased food intake. A large number of koi showed a typical female genital pore but at the same time also showed typical male secondary sex characteristics, such as tubercles on the head and the body.

\section{Macroscopy}

Most $(90 \%, \mathrm{n}=105)$ of the tumours were of a considerable size, accounting for between 10 and $30 \%$ of 


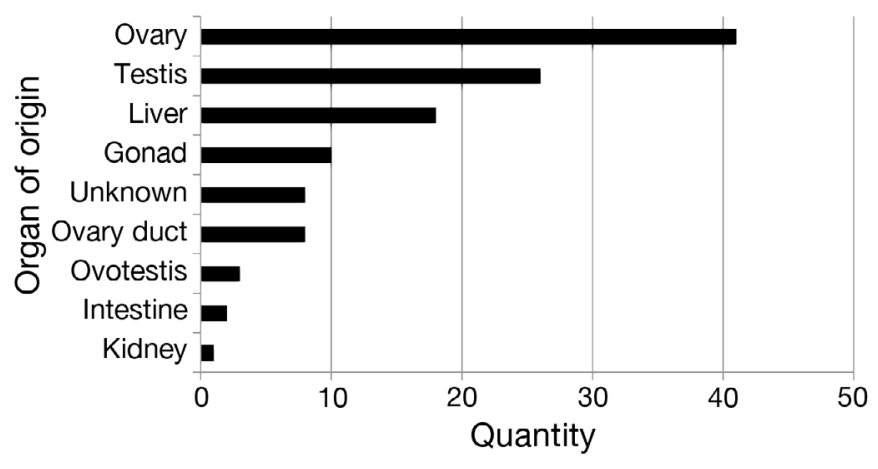

Fig. 3. Organ of tumour origin in koi Cyprinus carpio koi $(\mathrm{n}=117)$

the affected animal's body weight. In 62 cases, the neoplastic masses were evaluated macroscopically; $95 \%$ ( $\mathrm{n}=59$ ) were whitish, multinodular masses. Of these 59 neoplastic masses, $71 \%(n=42)$ showed few to many cysts of various sizes, filled with either yellowish or reddish fluid (Fig. 2a,b), and $29 \%(\mathrm{n}=17)$ were compact without cysts. All of these masses were of cheesy texture, sometimes with a friable centre. The remaining $5 \%(n=3)$ of the neoplastic masses showed a multinodular and cystic appearance, in most parts of dark red colour with few whitish nodular parts. These neoplasms contained multiple cysts of variable size, filled with dark reddish fluid.

\section{Sex and organ of origin}

Of the tumours, $48.7 \%(n=57)$ were found in female fish and $24.8 \%(\mathrm{n}=29)$ originated from male koi. Tumours from hermaphrodites represented only $2.6 \%(n=3)$. In $23.9 \%(n=28)$ of the cases, the sex was macroscopically and histologically unidentifiable. These cases were classified as 'sex unknown'.

The ovary was the most commonly affected organ (35\%, $\mathrm{n}=41$; Fig. 3), followed by the testis $(22.2 \%$, $\mathrm{n}=26)$ and the liver $(15.4 \%, \mathrm{n}=18)$. The remaining tumours presumptively originated from gonadal tissue that could not be clearly assigned to either sex $(10.3 \%, \mathrm{n}=12)$, or from the oviduct $(6.8 \%, \mathrm{n}=8)$, ovotestis $(2.6 \%, \mathrm{n}=3)$, intestine $(1.7 \%, \mathrm{n}=2)$, kidney $(0.9 \%, \mathrm{n}=1)$ or from unknown origin $(5.1 \%, \mathrm{n}=6)$.

\section{Tumour classification}

Out of 90 tumours associated with the reproductive system, $81 \%(n=73)$ originated exclusively from stromal tissue of the sex-cord, either in the ovary, testis, ovotestis or unidentifiable gonads, and were subsequently classified as sex-cord stromal tumours (Table 3, Fig. 3). In 1 case, an undifferentiated sarcoma was diagnosed. In IHC, all of these tumours stained negative for CK AE1/AE 3 and E-cad. Twelve tumours $(13.3 \%)$ originated from epithelial cells of the oviduct $(n=8)$ or the germinal epithelium of the gonads $(\mathrm{n}=4)$ and were subsequently classified as carcinomas (Table 3). These tumour types stained positive for E-cad in IHC with a varying amount of positive cells throughout the neoplastic mass. Staining with $\mathrm{CK}$ AE1/AE 3 was inconclusive. Of the gonadal neoplastic lesions, 3.3\% (n=3) were classified as germ cell tumours, 2 seminomas and 1 germ cell tumour in an unidentifiable gonad (Table 3, Fig. 4; IHC results are presented below). In 1 hybrid, a mixed germ cell-sex-cord stromal tumour was diagnosed.

Out of 18 tumours originating from the liver, $77.8 \%$ ( $n=14$ ) were classified as hepatocellular carcinomas (Fig. 5; IHC results are presented below), 11.1\% ( $\mathrm{n}=$ $2)$ as undifferentiated sarcomas and $11.1 \%(n=2)$ as haemangiomas.

The 2 intestinal neoplasms were diagnosed as adenocarcinomas, both staining positive with CK AE1/ AE 3 and E-cad. The kidney tumour was also diagnosed as a carcinoma, originating from the tubular epithelial cells.

Table 3. Overview of the tumours and their characterizations in koi Cyprinus carpio koi. Score values are described in Table 2

\begin{tabular}{|c|c|c|c|c|c|c|c|}
\hline \multirow[t]{2}{*}{ Tumour type } & \multicolumn{2}{|c|}{ Prevalence } & \multicolumn{5}{|c|}{ Tumour growth score measurements (median, $25^{\text {th }}-75^{\text {th }}$ percentiles) } \\
\hline & Organ & Frequency & $\begin{array}{l}\text { Cell } \\
\text { atypia }\end{array}$ & $\begin{array}{l}\text { Mitotic } \\
\text { frequency }\end{array}$ & Necrosis & $\begin{array}{l}\text { Infiltrative } \\
\text { growth }\end{array}$ & Encapsulation \\
\hline $\begin{array}{l}\text { Sex-cord } \\
\text { stromal tumour }\end{array}$ & $\begin{array}{l}\text { Ovary } \\
\text { Testis }\end{array}$ & $\begin{array}{l}40 / 117 \\
23 / 117\end{array}$ & $2(1-2)$ & $1(1-2)$ & $2(2-2)$ & $2(0-2)$ & $0(0-0)$ \\
\hline Germ cell tumour & $\begin{array}{l}\text { Testis } \\
\text { Gonad }\end{array}$ & $\begin{array}{l}2 / 117 \\
1 / 117\end{array}$ & $1(0.5-1.5)$ & $1(1-1.5)$ & $1(1-2)$ & $2(2-2)$ & $1(0.5-1)$ \\
\hline Carcinoma & $\begin{array}{l}\text { Ovary } \\
\text { Liver }\end{array}$ & $\begin{array}{c}1 / 117 \\
14 / 117\end{array}$ & $\begin{array}{l}2(2-2) \\
1(1-2)\end{array}$ & $\begin{array}{l}1(1-1) \\
1(1-1)\end{array}$ & $\begin{array}{l}2(2-2) \\
2(2-2)\end{array}$ & $\begin{array}{l}0(0-0) \\
1(1-1)\end{array}$ & $\begin{array}{l}1(1-1) \\
0(0-1)\end{array}$ \\
\hline
\end{tabular}



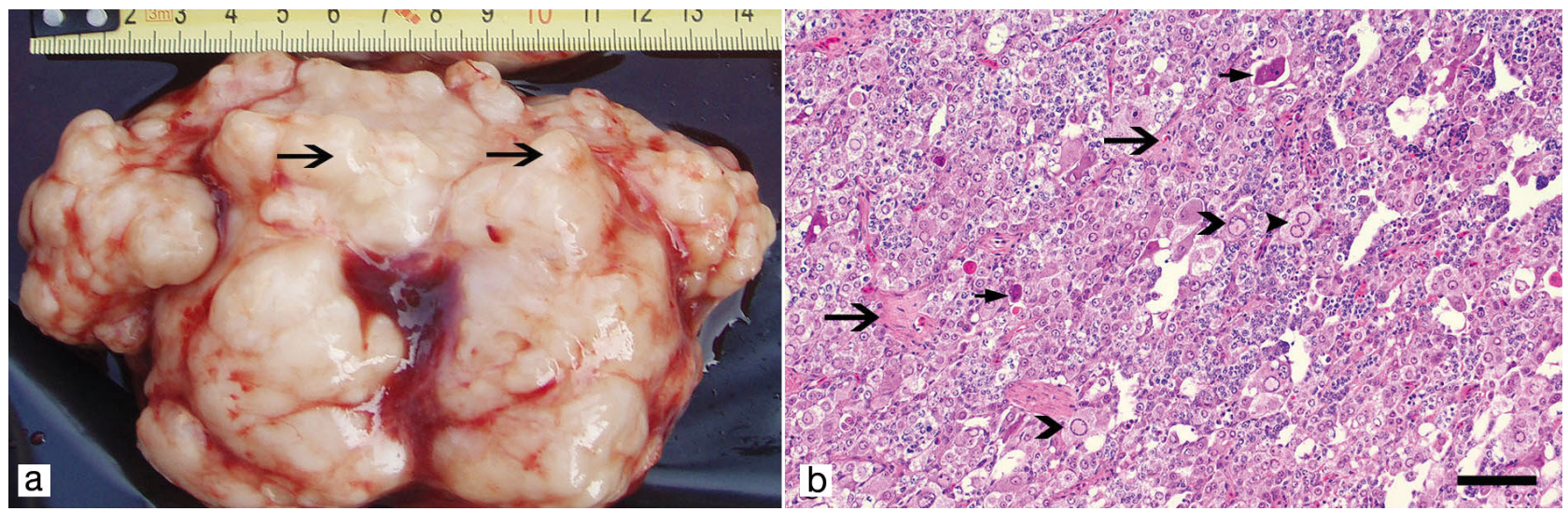

Fig. 4. Germ cell tumour in testis of koi Cyprinus carpio koi. (a) Macroscopic appearance: whitish, multinodular solid mass (arrows with open arrowhead). (b) Microscopic appearance: tumour cells grow in groups with a scant amount of fibrovascular stroma (arrows with open arrowhead); tumour cells are heterogeneous in size and shape with small to large, round to oval or polygonal cells, with a moderate to high amount of amphophilic cytoplasm; nuclei differ in appearance from small hyperchromatic to megakaryotic (open arrowheads), round, oval or polygonal nuclei, occasionally with multiple nuclei (closed arrowhead), scattered necrotic cells (arrows with closed arrowhead). H\&E staining; scale bar $=25 \mu \mathrm{m}$

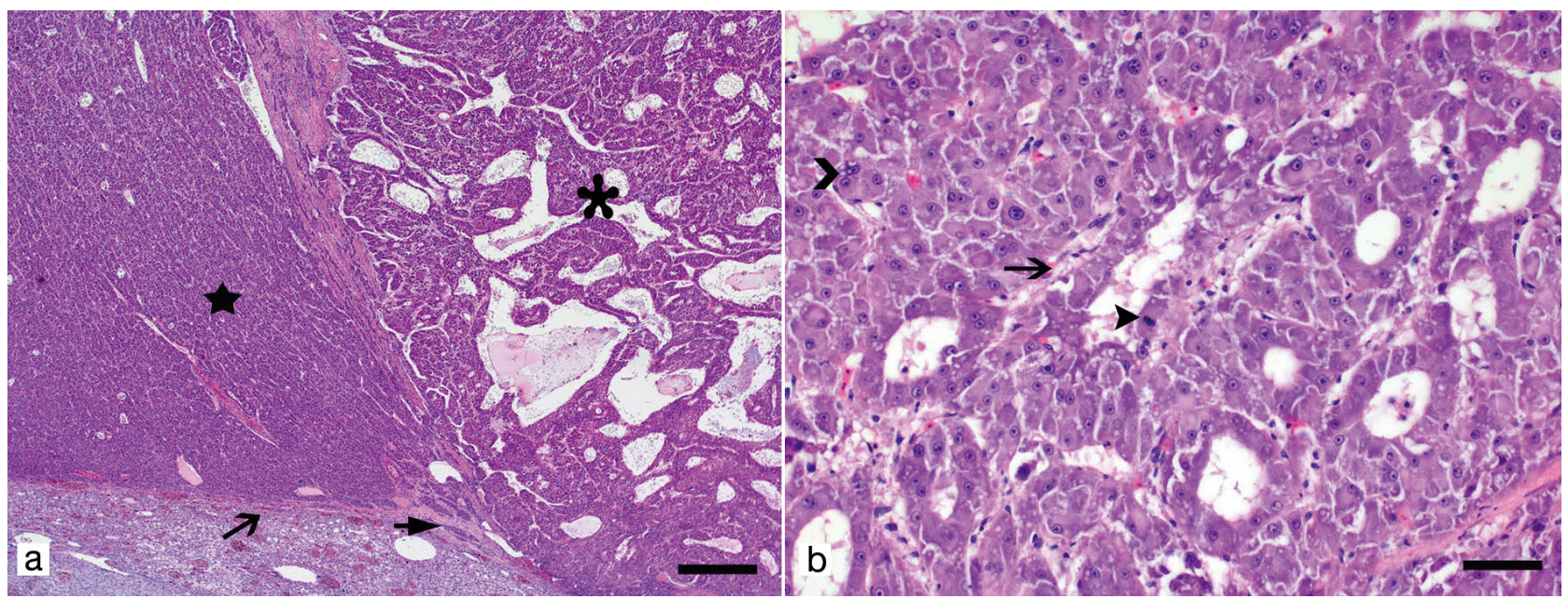

Fig. 5. Hepatocellular carcinoma in liver of koi Cyprinus carpio koi. (a) Two different types of hepatocellular carcinoma are present, one solid part (star) and a trabecular part (asterisk); tumour mass is partly encapsulated (arrow with open arrowhead), mostly well demarcated, occasionally infiltrating into the surrounding tissue (arrow with closed arrowhead). (b) Higher magnification of trabecular part. Tumour cells are mostly arranged in cords with a moderate amount of fibrovascular stroma (arrow with open arrowhead); tumour cells are cuboidal to polygonal, with a low to moderate amount of basophilic or amphophilic cytoplasm, and round to oval, central nuclei, occasionally binucleated cells (open arrowhead) and mitotic figures (closed arrowhead) are present. H\&E staining; scale bars = (a) $50 \mu \mathrm{m}$, (b) $25 \mu \mathrm{m}$

\section{Tumour characterization}

Sex-cord stromal tumours

Out of 117 tumours, 73 were identified as sex-cord stromal tumours; of these, 40 originated from the ovary, 23 from the testis, 8 from unidentifiable gonads and 2 from the ovotestis (Table 3 ).

Neoplastic cells were mostly arranged in groups or bundles with a small to moderate amount of fibrovascular stroma. In most cases, there were 2 types of tumour cells: polygonal cells with moderate amounts of often vacuolated cytoplasm and oval to pleomorphic, centrally located nuclei; and elongated cells with granular cytoplasm and small oval to elongated centrally located nuclei (Fig. 2c). Of the sex-cord stromal tumours (from the ovary, testis, ovotestis and unidentifiable gonads), $67 \%(\mathrm{n}=49)$ were not encapsulated and showed infiltrative growth. The remaining $33 \%(n=24)$ of the tumours were partially encapsulated and did not show infiltrative growth (Table 3). 
Table 4. Statistical association between the different histopathological characteristics from 74 sex-cord tumours in koi Cyprinus carpio koi using median comparisons (Kruskal-Wallis Test; KWT) with Dunn's multiple comparison correction (MCT; $z$-value $>2.349$ ) and Fisher's exact test (FET) from pairwise cross tabulation

\begin{tabular}{|c|c|c|c|c|c|c|}
\hline Variables (classes) & Median (rank) & Median (rank) & Median (rank) & KWT & Dunn's MCT & FET \\
\hline & Anaplasia (0) & Anaplasia (1) & Anaplasia (2) & $\mathrm{p}$ & $z>2.394$ & $\mathrm{p}$ \\
\hline Necrosis $(0,1,2)$ & $2(37.4)$ & $2(28.1)$ & $2(40.0)$ & 0.055 & $1-2$ & 0.023 \\
\hline Mitosis $(0,1,2)$ & $1(26.0)$ & $1(36.0)$ & $1(39.8)$ & 0.011 & $0-2$ & 0.007 \\
\hline Infiltrative growth $(0,1,2)$ & $0(28.6)$ & $2(40.2)$ & $2(40.9)$ & 0.029 & $0-2$ & 0.027 \\
\hline \multirow[t]{2}{*}{ Encapsulation $(0,1)$} & $0(34.0)$ & $0(31.3)$ & $0(31.5)$ & 0.813 & & 0.907 \\
\hline & Necrosis $(0)$ & Necrosis (1) & Necrosis (2) & $\mathrm{p}$ & $z>2.394$ & $\mathrm{p}$ \\
\hline Mitosis $(0,1,2)$ & $1(33.4)$ & $0.5(16.3)$ & $1(37.3)$ & 0.045 & $1-2$ & 0.057 \\
\hline Infiltrative growth $(0,1,2)$ & $1.5(31.7)$ & $0.5(24.0)$ & $2(39.4)$ & 0.126 & & 0.014 \\
\hline \multirow[t]{2}{*}{ Encapsulation $(0,1)$} & $0(32.0)$ & $0.5(40.8)$ & $0(31.7)$ & 0.634 & & 0.840 \\
\hline & Mitosis (0) & Mitosis (1) & Mitosis (2) & $\mathrm{p}$ & $z>2.394$ & $\mathrm{p}$ \\
\hline Infiltrative growth $(0,1,2)$ & $0(17.7)$ & $2(38.0)$ & $2(33.8)$ & 0.029 & $0-1$ & 0.054 \\
\hline \multirow[t]{2}{*}{ Encapsulation $(0,1)$} & $0(23.5)$ & $0(29.0)$ & $0(33.3)$ & 0.435 & & 0.748 \\
\hline & Infiltrative growth $(0)$ & Infiltrative growth (1) & Infiltrative growth (2) & $\mathrm{p}$ & $z>2.394$ & $\mathrm{p}$ \\
\hline Encapsulation $(0,1)$ & $0(36.3)$ & $1(56.5)$ & $0(29.7)$ & 0.008 & $1-2$ & 0.009 \\
\hline
\end{tabular}

Of these 73 cases, $71 \%(n=52)$ showed no $(0$ mitotic figures $\mathrm{HPF}^{-1}$ ) to low numbers (1-2 mitotic figures $\left.\mathrm{HPF}^{-1}\right)$ of mitotic figures, while in $29 \%(\mathrm{n}=21)$, intermediate numbers (5 mitotic figures $\mathrm{HPF}^{-1}$ ) were found. The frequency of mitotic figures (median of score values) was $1 \mathrm{HPF}^{-1}$ (25th-75th percentiles = $1-2)$ (Table 3). Over half (56\%, n = 41) of the tumours showed a high degree of cell atypia in neoplasms with both high and low numbers of mitotic figures. However, the level of anaplasia was significantly associated with the occurrence of necrosis (KWT, $\mathrm{p}=0.055$; FET, $p=0.023$ ), the frequency of mitotic figures (KWT, $\mathrm{p}=0.011 ; \mathrm{FET}, \mathrm{p}=0.007$ ) and the level of infiltrative growth (KWT, p = 0.029; FET, $\mathrm{p}=0.027$ ). The extent rate of necrosis was weakly associated with the frequency of mitotic figures (KWT, p = 0.045; FET, p = 0.057 ) and the level of infiltrative growth (KWT, p = $0.126 ; \mathrm{p}=\mathrm{FET}, \mathrm{p}=0.014$ ). Frequency of mitotic figures and level of infiltrative growth was also weakly associated $(K W T, p=0.029$; FET, $\mathrm{p}=0.054)$. Encapsulation and infiltrative growth were significantly associated (KWT, p = 0.008; FET, p = 0.009; Table 4).

Sex-cord stromal tumours that were investigated by IHC (33 out of 73) stained negative for CK AE1/AE 3 and E-cad.

\section{Germ cell tumours}

Three out of 117 tumours $(2.5 \%)$ were classified as germ cell tumours (Table 3 ). Two tumours originated from male koi, and in 1 animal, the sex was not identifiable.
Histologically, the germ cell tumours were not or only partially encapsulated and mostly showed infiltrative growth. Tumour cells grew in groups with a moderate amount of fibrovascular stroma. Tumour cells were large, round to oval or polygonal, with a moderate to high amount of amphophilic, sometimes vacuolated cytoplasm (Fig. 4). The nuclei differed in appearance from small hyperchromatic to vacuolated megakaryotic round, oval or polygonal with granular chromatin. Multinucleated cells with up to 3 nuclei were present (Fig. 4b). Two tumours showed low numbers of mitotic figures, and one showed a high number of mitotic figures. All 3 tumours showed different degrees of cell atypia (none, medium, high), often with multiple areas of necrosis.

IHC staining performed on 1 germ cell tumour revealed no positive signal for either CK AE1/AE 3 or E-cad.

\section{Liver tumours}

Out of 117 tumours, 18 originated from the liver $(15.3 \%)$. Of these, 14 were identified as hepatocellular carcinomas (Table 3, Fig. 5). The remaining 4 neoplasms were diagnosed as 2 sarcomas and 2 haemangiomas.

Histologically, the hepatocellular carcinomas were not or only partially encapsulated and showed a moderate degree of cell atypia. Tumour cells were mostly arranged in cords with a moderate amount of fibrovascular stroma. Tumour cells were cuboidal to polygonal, with a low to moderate amount of baso- 
philic or amphophilic, sometimes vacuolated, cytoplasm and round to oval, centrally located nuclei (Fig. 5c). The number of mitotic figures was low to moderate, and small areas of necrosis were present throughout the neoplasms. Most of the carcinomas showed scattered infiltration by mainly lymphocytes and few macrophages. For median values and quartiles of the growth characteristics (cell atypia, frequency of mitotic figures, necrosis, encapsulation or infiltrative growth), see Table 3.

IHC revealed positive staining for E-cad in all 8 examined tumours with varying percentages of positive cells throughout the neoplastic mass. Staining with CK AE1/AE 3 was inconclusive.

\section{DISCUSSION}

The aim of the present study was to gain more information about the frequency and the nature of coelomatic neoplasms in ornamental carp. Specifically, we wanted to investigate sex-specific differences, affected organs as well as growth characteristics of the neoplasms to gain more information about a possible prognosis. The prognosis was judged by the encapsulation versus invasiveness of the neoplastic masses, the degree of cell atypia, the number of mitotic figures as an indication for the growth capacity and the degree of necrosis. Furthermore, IHC using E-cadherin can be used as an indicator for invasiveness, especially for neoplasms of epithelial origin, as this cell type regularly showed positivity in normal carp tissue. E-cadherin acts as an invasion suppressor molecule, mainly expressed in non-invasive, well-differentiated tumour types. Alternatively, with increasing invasiveness, expression is suppressed (Vleminckx et al. 1991, Singhai et al. 2011).

Romano et al. (2013) showed that neoplasms in ectotherms are comparable to the corresponding neoplastic processes of endotherms with regard to their structure and behaviour. As in mammals, growth factors can also be used to categorize tumours of ecoothermic vertebrates (Cullen et al. 2002). To distinguish between benign and malignant neoplasms, which is essential for prognosis, 4 main parameters are used in mammal tumour classification: (1) differentiation and anaplasia, (2) rate of growth, (3) local invasion and (4) metastasis. In fish, however, metastases are less common, possibly because several common metastatic primary tumours in mammals (lung, breast, cervix, prostate and uterus) and some of the most frequent sites of metastases (lungs, lymph nodes and bone marrow) are not present in fish. Other reasons for the less frequent occurrence of metastases in fish compared with mammals have been proposed, including differences in the lymphatic system and lower body temperature of fish (Grizzle \& Goodwin 2010). In our study, no metastases were detected. Because one of the key features of malignancy is missing, tumour classification into benign or malignant in fish is often more difficult compared to mammals. In this study, classification was based on demarcation, invasion, degree of cell anaplasia, frequency of mitotic figures and necrosis.

IHC was applied in this study to first identify cell types of epithelial origin (CK AE1/AE 3 or E-cad) and second to give a possible hint of invasiveness (E-cad). Because of the lack of reliable mesenchymal markers in koi carp tissue, application was restricted to these epithelial markers. CK AE1/AE 3 clearly identified intestinal epithelial cells, also shown before (Dale et al. 2009); however, in the gonad and in the liver, staining was inconclusive. This staining pattern was confirmed by our results in the reference carp tissue, with hepatocytes staining negative and inconsistent staining in ovary epithelial cells. However, as bile duct epithelial cells were clearly positive, this antibody can be used to further distinguish between hepatocellular and bile duct carcinoma. E-cad staining was positive in all cells of epithelial origin, with a varying amount of positive cells throughout the neoplastic masses. However, in masses of mesenchymal origin, staining was always negative in our material.

\section{Sex-specific differences}

The number of koi with coelomatic tumours included in this study was 117 . Nearly half of the affected koi were female, $23.9 \%$ were of unidentifiable sex (both macroscopically and histologically), and only $24.8 \%$ were male. To our knowledge, there are no exact figures on the proportion of male and female koi in Switzerland or in other countries or populations. Due to the fact that sex in carp is genetically determined and not influenced by environmental factors, we estimate the ratio of female to male to be about 50:50. This is supported by Donkers et al. (2012), who found the sex ratio of wild carp in a lake in Tasmania to be nearly 50:50. Our results therefore indicate that female koi are more prone to develop coelomatic tumours than male koi (2:1). This fact has also been described by Ishikawa \& Takayama (1977); the authors reported a 
survey of 21 ovarian neoplasms in adult koi, occurring from 1974 to 1976 . The neoplasms were common in sexually mature female koi. Baumann et al. (1990) described brown bullheads Ictalurus nebulosus in North America developing liver tumours, with old age and female sex being identified as significant risk factors. However, the reason for these sexspecific differences in brown bullheads remained unclear. In contrast, Granado-Lorencio et al. (1987) found tumours in the gonads only in male hybrids of Crucian carp Carassius carassius crossed with the common carp Cyprinus carpio.

Based on our practical experience, more than $90 \%$ of adult koi are sexually identifiable as either female or male. Within tumour cases in our study, there was a surprisingly high number of koi of macroscopically unidentifiable sex even at necropsy. Histologically, there were no germ cells visible in these cases. We suspect higher numbers of coelomatic tumours in fish that are sexually not differentiated and which are therefore classified as sterile. This is in agreement with Sonstegard (1977) and Leatherland \& Sonstegard (1977), who showed that many sterile hybrids of carp and goldfish Carassius auratus developed gonadal tumours. These authors did not describe the differentiation stage of the gonads; therefore, a comparison regarding the differentiation status of the fish between the different studies is not possible. Gonadal tumours in the carp/goldfish hybrids first became evident in 3 to $4 \mathrm{yr}$ old fish, the age at which carp and goldfish normally become sexually mature. This age class is comparable to our study, as we found the highest number of fish with coelomatic neoplastic lesions in the age class of 3 to $6 \mathrm{yr}$ (Ott Knüsel et al. 2015).

\section{Organ of origin}

Gonadal tissue was the predominant organ of origin of coelomatic tumours in our study, with $77 \%$ of all cases originating from the gonadal tissue: either ovary, testis, ovotestis, unidentified gonads or oviduct. In fish pathology in general, tumours of the gonadal tissue are considered to be a rare finding (Groff 2004). In different cyprinid species, however, a high prevalence of these tumours is described. Sonstegard (1977) reported an overall prevalence of gonadal tumours in wild populations of carp of $0.57 \%$, in goldfish of $4.1 \%$ and in hybrids between carp and goldfish of up to $100 \%$ in the Great Lakes. Granado-Lorencio et al. (1987) found gonadal tumours in more than $10 \%$ of specimens captured in the various basins of the Tagus and Guadiana Rivers in Spain. These tumours appeared within a limited size range of fish corresponding to the age of approximately 4 yr. Ishikawa \& Takayama (1977) stated that ornamental carp with complex genetic histories developed ovarian neoplasms that may have been hereditary in nature. Our study indicates that koi carp kept in captivity are also prone to developing gonadal tumours.

\section{Tissue of origin and growth characteristics}

\section{Sex-cord stromal tumours}

The predominant tissue of origin for male and female koi was the sex-cord stromal tissue. Sex-cord stromal tumours are derived from the cellular constituents of the ovary and testis, other than epithelium or germ cells (Sertoli and Leydig cells for the testis, theca and granulosa cells for the ovary). A characteristic of these tumours is the coexistence of multiple cell types in the same tumour. The term 'sex-cord stromal' reflects the uncertainty of the embryologic origin of cells in these tumours.

In our study, the main affected age class of the investigated koi was between 3 and $6 \mathrm{yr}$, the time period when koi become sexually mature. Sex-cord stromal tumours in mammals have the potential to be hormonally active. Ovarian sex-cord stromal tumours can secrete a diverse mixture of female and male hormones. These hormones can influence the reproductive behaviour of the affected animal (MacLachlan \& Kennedy 2002). Similar endocrine effects could be a possible explanation for the high proportion of koi in our study that showed a typical female genital pore but also showed typical features for a male, such as tubercles on the head and the body. These tubercles are usually seen on sexually mature male koi, especially during the spawning season, and are therefore used by hobbyists and breeders as a simple way to identify male koi. However, there are no data available about the secretory capacity of the gonadal tumours in koi.

Malignant sex-cord stromal tumours in mammals are mostly disorganized and can exhibit cell atypia with numerous mitotic figures, foci of necrosis and vascular invasion by the tumour cells (MacLachlan \& Kennedy 2002). This is in agreement with the histological characteristics of the sex-cord stromal tumours in our study, which showed a medium to high degree of cell atypia, an elevated frequency of mitotic figures and small to large foci of necrosis. 


\section{Germ cell tumours}

Only 4 out of 117 tumours in this study were classified as germ cell tumours or mixed germ cellsex-cord stromal tumours. Two tumours originated from male koi, 1 from a hybrid koi, and in 1 animal, the sex was not identifiable. The few cases are in agreement with the findings in domestic animals, where germ cell tumours are a rare finding, with seminoma being the only tumour that occurs frequently, mostly in animals of advanced age (MacLachlan \& Kennedy 2002).

\section{Liver tumours}

In our study, 18 out of 117 tumours originated from the liver; 14 of them were identified as hepatocellular carcinomas. Hepatic neoplasms are not commonly reported in ornamental fish species (Groff 2004). Hepatic carcinomas in rainbow trout grown in hatcheries have been linked to feed contaminated with aflatoxin (Majeed et al. 1984, Martineau \& Ferguson 2006). Aflatoxin produced by Aspergillus sp. in contaminated fish feed is a known carcinogenic factor in fish and a possible contributor to the hepatocellular carcinomas in our study. In IHC, the amount of positively stained cells using the E-cadherin antibody varied between the cases and between different areas in a single tumour case, suggesting that this factor may be used as an indicator for loosening cell-cell adhesions and increasing invasiveness. Reactivity against E-cadherin has been used as a prognostic value in human cancers (e.g. Singhai et al. 2011), with decreasing expression in invasive neoplasms (Vleminckx et al. 1991, Singhai et al. 2011). Our results show that this parameter can also be used in carp epithelial tumours.

\section{CONCLUSIONS}

Groff (2004) stated that neoplasms in fish are generally less aggressive than neoplasms in mammals, and are most commonly discrete, focal, benign neoplasms with few exceptions. This is in contrast to our study, where all coelomatic tumours showed several signs of malignancy, which indicates that these tumours are likely to be fast-growing masses. These signs of malignancy and the late detection of a possible coelomatic tumour are associated with a poor prognosis. Our results indicate that female koi are more prone to developing coelomatic tumours and that the main organs of origin are the gonads. Within the gonads, the main cells of origin are cells of the stroma. More studies are needed to compare our results with other populations of koi and other species.

Acknowledgements. We thank Dr. med. vet. Heinzpeter Schwermer for providing the demographic overview and Dr. med. vet. Isabel Imboden for revising the English language. Additionally, we thank Dr. Oliver Hochwartner and Dr. Achim Bretzinger for providing tumour cases from Austria and Germany.

\section{LITERATURE CITED}

Baumann PC, Harshbarger JC, Hartman KJ (1990) Relationship between liver tumors and age in brown bullhead populations from two Lake Erie tributaries. Sci Total Environ 94:71-87

> Bunton TE (1993) The immunocytochemistry of cytokeratin in fish tissues. Vet Pathol 30:418-425

Carey JR, Judge DS (2000) Longevity records: life spans of mammals, birds, amphibians, reptiles, and fish. Odense University Press, Odense

Cullen JM, Page R, Misdrop W (2002) An overview of cancer pathogenesis, diagnosis and management. In: Meuten DJ (ed) Tumors in domestic animals, $4^{\text {th }}$ edn. Iowa State Press, Ames, IA, p 3-44

Dale OB, Torud B, Kvellestad A, Koppang HS, Koppang EO (2009) From chronic feed-induced intestinal inflammation to adenocarcinoma with metastases in salmonid fish. Cancer Res 69:4355-4362

Donkers P, Patil JG, Wisniewski C, Diggle JE (2012) Validation of mark-recapture population estimates for invasive common carp, Cyprinus carpio, in Lake Crescent, Tasmania. J Appl Ichthyol 28:7-14

> Granado-Lorencio C, Garcia-Novo F, Lopez-Campos J (1987) Testicular tumors in carp-funa hybrid: annual cycle and effect on a wild population. J Wildl Dis 23: 422-427

Grizzle JM, Goodwin AE (2010) Neoplasms and related disorders. In: Leatherland JF, Woo PTK (eds) Fish diseases and disorders. Vol 2: Non-infectious disorders, neoplasms and related disorders, $2^{\text {nd }}$ edn. CAB International, Wallinford, p 19-84

Groff JM (2004) Neoplasia in fishes. Vet Clin North Am Exot Anim Pract 7:705-756

Head KW, Cullen JM, Dubielzig RR, Else RW and others (2003) Histological classification of tumors of the alimentary system of domestic animals, $2^{\text {nd }}$ Ser, Vol 10. Armed Forces Institute of Pathology, American Registry of Pathology, Washington, DC

Ishikawa T, Takayama S (1977) Ovarian neoplasia in ornamental hybrid carp (nishikigoi) in Japan. Ann NY Acad Sci 298:330-341

Kennedy P, Cullen J, Edwards M, Goldschmidt M, Larsen S, Monson L, Nielsen S (1998) Histological classification of tumors of the genital system of domestic animals, $2^{\text {nd }}$ Ser, Vol 4. Armed Forces Institute of Pathology, American Registry of Pathology, Washington, DC

Knüsel R, Brandes K, Lechleiter S, Schmidt-Posthaus H (2007) Two independent cases of spontaneously occur- 
ring branchioblastomas in koi carp (Cyprinus carpio). Vet Pathol 44:237-239

Leatherland JF, Sonstegard RA (1977) Structure of normal testis and testicular tumors in cyprinids from Lake Ontario. Cancer Res 37:3151-3168

Majeed SK, Jolly DW, Gopinath C (1984) An outbreak of liver cell carcinoma in rainbow trout, Salmo gairdneri Richardson in the UK. J Fish Dis 7:165-168

Martineau D, Ferguson HW (2006) Neoplasia. In: Ferguson HW (ed) Systemic pathology of fish. Scotian Press, London, p 313-335

Meuten D, Everitt J, Inskeep W (2007) Histological classification of tumors of the urinary system of domestic animals, $2^{\text {nd }}$ Ser, Vol 11. Armed Forces Institute of Pathology, American Registry of Pathology, Washington, DC

Ng ANY, de Jong-Curtain TA, Mawdsley DJ, White SJ and others (2005) Formation of the digestive system in zebrafish: III. Intestinal epithelium morphogenesis. Dev Biol 286:114-135

Ott Knüsel F, Doherr MG, Knüsel R, Wahli T, SchmidtPosthaus H (2015) Risk factors for development of internal neoplasms in koi carp Cyprinus carpio koi. Dis Aquat Org 114:199-207

Editorial responsibility: Thomas Lang, Cuxhaven, Germany
Romano LA, Klosterhoff M, Fuhr F, Rodrigues RV and others (2013) Neoplasia of the Sertoli cells in wild carp, Cyprinus carpio: optical, immunohistochemical and ultrastructural study. Bull Eur Assoc Fish Pathol 33:85-89

Singhai R, Patil VW, Jaiswal SR, Patil SD, Tayade MB, Patil AV (2011) E-Cadherin as a diagnostic biomarker in breast cancer. N Am J Med Sci 3:227-233

Sirri R, Mandrioli L, Grieco V, Bacci B, Brunetti B, Sarli G, Schmidt-Posthaus H (2010) Seminoma in a koi carp Cyprinus carpio: histopathological and immunohistochemical findings. Dis Aquat Org 92:83-88

Sirri R, Brachelente C, Schmidt-Posthaus H, Vitellozzi G, Mandrioli L (2012) Ultrastructural findings of spontaneously occurring seminoma in an adult ornamental cyprinid (Cyprinus carpio L.). Bull Eur Assoc Fish Pathol 32:19-23

Sonstegard RA (1977) Environmental carcinogenesis studies in fishes of the Great Lakes of North America. Ann NY Acad Sci 298:261-269

> Vleminckx K, Vakaet L, Mareel M, Fiers W, Von Roy F (1991) Genetic manipulation of E-cadherin expression by epithelial tumor cells reveals an invasion suppressor role. Cell 66:107-119

Submitted: March 16, 2015; Accepted: April 4, 2016 Proofs received from author(s): May 20, 2016 